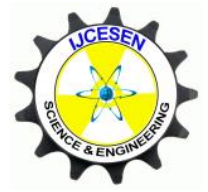

Copyright (C) IJCESEN
International Journal of Computational and

Experimental $\boldsymbol{S}$ cience and $\boldsymbol{E N g i n e e r i n g}$

(IJCESEN)

Vol. 6-No.1 (2020) pp. 7-12

http://dergipark.org.tr/tr/pub/ijcesen

Research Article

\title{
Determining the Best Maternity Hospital by Using a Fuzzy Decision Making Model
}

\author{
Billur ECER ${ }^{1}$, Ahmet AKTAŞ ${ }^{2 *}$, Mehmet KABAK ${ }^{2}$, Metin DAGDEVİREN ${ }^{2}$ \\ ${ }^{1}$ Ankara Yıldırım Beyazıt University, Department of Industrial Engineering, Ankara, Turkey \\ ${ }^{2}$ Gazi University, Department of Industrial Engineering, Ankara, Turkey \\ * Corresponding Author : aaktas@gazi.edu.tr \\ ORCID: 0000-0002-4394-121X
}

\section{Article Info:}

DOI: $10.22399 /$ ijcesen.646157

Received : 12 November 2019

Accepted : 12 February 2020

\section{Keywords}

Multiple Criteria Decision Making

Analytic Hierarchy Process

Triangular Fuzzy Sets

Healthcare Management

\begin{abstract}
$\underline{\text { Abstract: }}$
Despite having child brings great responsibility, people want to have a child instinctively. In the context of childcare, parental responsibility requires that children should be born in good conditions and grow healthy and happily. Parents' first responsibility is to ensure that children born in a healthy way. Nowadays, pregnant women visit doctor regularly and monitor the infant development. There are too many doctors and hospitals working in obstetrics area. The increasing number of alternatives and selection criteria makes it difficult to find a compromise solution in terms of conflicting selection criteria. Therefore, using analytical methods becomes necessary while making the decision of hospital choice for pregnancy follow-up. The main aim of this study is to develop a decision tool for determining the best hospital for pregnancy process. Because of the existence of linguistic evaluations in the decision process, Fuzzy Analytic Hierarchy Process is used in this study for determining the best alternative. An application of a real world problem is presented to demonstrate the applicability of the proposed methodology. Within the presented application weight of hospital selection criteria and priority values of five predetermined alternative hospitals in Ankara are calculated are determined. The obtained results of the study shows that staff quality and technical conditions are the most important criteria for hospital selection.
\end{abstract}

\section{Introduction}

Having a child brings some responsibilities, besides it is a great happiness for parents. For everything that the child needs, parents should present the best possible options for their children. Parents needs to analyze carefully before choosing an option. Wrong choices can lead vital problems for the child.

First responsibility of parents is to ensure that the child should be born in healthy conditions. During the pregnancy process, pregnant women visit obstetrics doctors regularly and monitor the baby's development. However, there are many alternative hospitals and doctors working on obstetrics field and making a choice between these alternatives requires considering different factors which are commonly conflicting. Multiple criteria decision making (MCDM) approaches are useful for such kind of problems with conflicting criteria and a number of alternatives [1]. In this study, a MCDM model is used to determine the best hospital for monitoring infant development. The MCDM model could combine triangular fuzzy sets and Analytic Hierarchy Process (AHP). Fuzzy is used in this study because of the thought of modelling the uncertainty of decision makers in comparison phase. The rest of the paper organized as follows: The methodology is explained in the second part. Next, determination of the best maternity hospital via Fuzzy AHP is given with application steps in the Third Part. Conclusions and suggestions for further studies are presented in the fourth part.

\section{Methodology}

\subsection{Analytic Hierarchy Process}


In this study, hospital selection for monitoring infant development is made via AHP. AHP technique is proposed by Saaty in 1977 [2]. In different studies, various fuzzy extensions of AHP are proposed by researchers to cope with the difficulty of judgement of qualitative factors [3]. Some applications of AHP can be listed as safety assessment of shipping routes [4], management of intellectual capital assets [5], agricultural product warehouse site selection [6], selection of safety devices of industrial machinery [7], information technology selection [8], current bank account selection [9], supplier selection [10], ERP system selection [11].

AHP is a quantitative method that is used by researchers commonly in decision problems concerning with selection among alternatives by considering their relative performance in terms of several criteria. The main advantage of AHP is to handle complex decision problems in a hierarchical structure. By this way, obtaining the solution of decision problem becomes easier. Importance degree of criteria and priorities of alternatives are being determined through pairwise comparisons and these obtained values are used to make the decision. The decision process via AHP involves six steps [3]:

- Describing the decision problem,

- Determination of decision criteria and alternatives,

- Construction of pair wise comparison matrices,

- Determination of the consistency index of the matrix,

- Calculation of relative weights of decision criteria and alternatives, and

- Making the decision.
A one-way hierarchical structure between problem goal, decision criteria and alternatives as shown in Figure 1 is being used in AHP.

Pairwise comparison matrices are constructed by using $1-9$ scale proposed by Saaty [2]. Elements of $1-9$ scale and their definitions are given in Table 1.

Table 1. 1 -9 scale for pairwise comparisons [2]

\begin{tabular}{|l|l|}
\hline Importance Score & Definition \\
\hline 1 & Equal importance \\
\hline 3 & Moderate importance \\
\hline 5 & Strong importance \\
\hline 7 & Very strong importance \\
\hline 9 & Absolute importance \\
\hline $2,4,6,8$ & Intermediate values \\
\hline
\end{tabular}

\subsection{Fuzzy Set Theory}

Fuzzy set theory (FST) is introduced to the literature by Zadeh in 1965 to deal with the uncertainty and vagueness [12]. The capability of representing uncertain data is the main advantage of FST. Unlike the binary relation between the element and the set in crisp sets, FST defines elements with a grade of membership to the set. Grade of membership is expressed by a membership function, which assigns each object a grade of membership between 0 and 1 [13]. A Triangular Fuzzy Number is shown with a symbol with tilde " " placed above the symbol like $\tilde{X}$. Assume that the parameters $\mathrm{a}, \mathrm{m}$ and $\mathrm{b}$ denote the smallest possible value, the most promising value and the largest possible value that describe the fuzzy event, respectively. An example representation of a TFN is given in Figure 2. Since the left and right sides of TFNs are linear, their membership functions for TFNs can be expressed as in the following form:

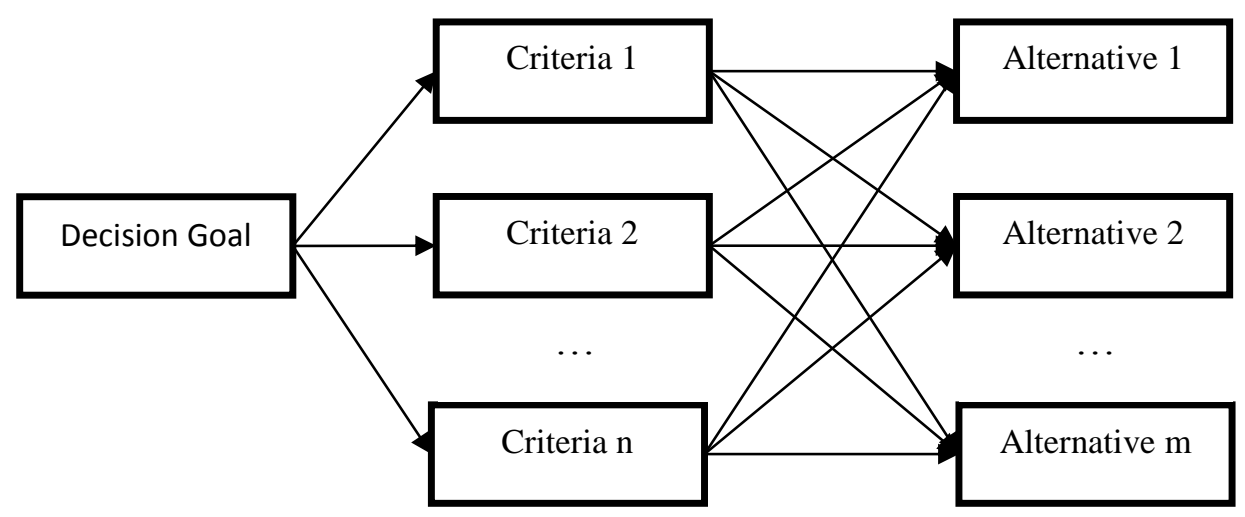

Figure 1. Hierarchical structure of a MCDM problem with $n$ criteria and $m$ alternatives 


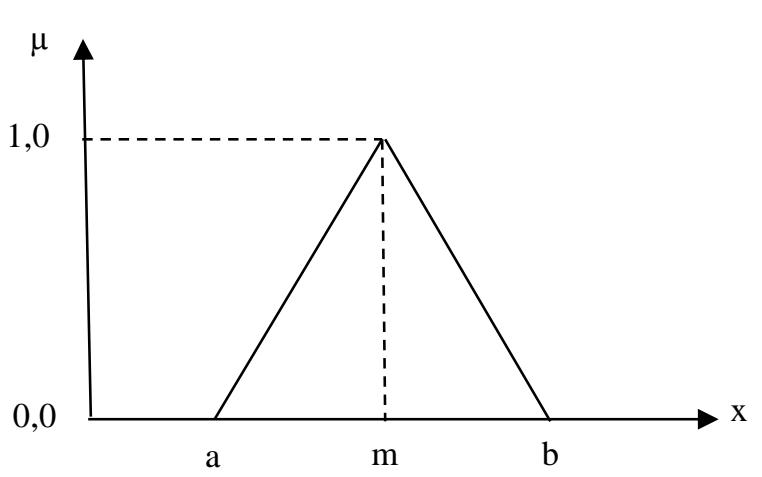

Figure 2. Representation of TFN $\tilde{X}$.

$$
\mu\left(\frac{x}{X^{0}}\right)= \begin{cases}0 & , x<l \\ \frac{x-a}{m-a} & , l \leq x \leq m \\ \frac{u-x}{u-m} & , m \leq x \leq u \\ 0 & , x>u\end{cases}
$$

An important advantage of FST is the applicability of mathematical operations on uncertain terms. There are many different mathematical operations can be applied on TFNs. The operators used in this study are defined as shown in equation 2 for two positive TFNs represented by $\left(\mathrm{a}_{1}, \mathrm{~m}_{1}, \mathrm{~b}_{1}\right)$ and $\left(\mathrm{a}_{2}, \mathrm{~m}_{2}, \mathrm{~b}_{2}\right)$

$$
\begin{aligned}
& \left(a_{1}, m_{1}, b_{1}\right)+\left(a_{2}, m_{2}, b_{2}\right)=\left(a_{1}+a_{2}, m_{1}+m_{2}, b_{1}+b_{2}\right) \\
& \left(a_{1}, m_{1}, b_{1}\right)-\left(a_{2}, m_{2}, b_{2}\right)=\left(a_{1}-a_{2}, m_{1}-m_{2}, b_{1}-b_{2}\right) \\
& \left(a_{1}, m_{1}, b_{1}\right) \times\left(a_{2}, m_{2}, b_{2}\right)=\left(a_{1} \times a_{2}, m_{1} \times m_{2}, b_{1} \times b_{2}\right) \\
& \left(a_{1}, m_{1}, b_{1}\right) \div\left(a_{2}, m_{2}, b_{2}\right)=\left(a_{1} \div b_{2}, m_{1} \div m_{2}, b_{1} \div a_{2}\right)
\end{aligned}
$$

\section{Application via Fuzzy Analytic Hierarchy Process}

In this section, the application steps of the method are given. The decision making group consists of five pregnant women. They are asked to determine the hospital selection criteria and possible alternative hospitals in Ankara. The group make judgements on criteria and alternative hospitals by brainstorming.

The steps of the application go on as follows:

Step 1: Hierarchical structure of the hospital selection decision is constructed. Criteria are determined as accessibility to the hospital (C1), quality of staff (C2), total expenses over all pregnancy process (C3), physical conditions (C4) and technical conditions (C5). Five popular private hospitals in Ankara are evaluated as alternatives by the decision making group. The names of the hospitals are not given here due to the commercial issues. Hierarchical structure of the decision problem is given in Figure 3.

Step 2: Fuzzy pairwise comparison matrices are formed according to decision making group's opinion. Fuzzy numbers proposed by Dağdeviren [3] and presented in Table 2 are used in comparisons. Pairwise comparison matrix for criteria evaluation is presented in Table 3.

Table 2. Fuzzy scale for pairwise comparisons [3]

\begin{tabular}{|c|c|c|c|}
\hline $\begin{array}{c}\text { Saaty's } \\
\text { Scale }\end{array}$ & $\begin{array}{c}\text { Fuzzy } \\
\text { Equivalent }\end{array}$ & $\begin{array}{c}\text { Saaty's } \\
\text { Scale }\end{array}$ & $\begin{array}{c}\text { Fuzzy } \\
\text { Equivalent }\end{array}$ \\
\hline 1 & $(1,1,1)$ & $1 / 1$ & $(1 / 1,1 / 1,1 / 1)$ \\
\hline 3 & $(1,3,5)$ & $1 / 3$ & $(1 / 5,1 / 3,1 / 1)$ \\
\hline 5 & $(3,5,7)$ & $1 / 5$ & $(1 / 7,1 / 5,1 / 3)$ \\
\hline 7 & $(5,7,9)$ & $1 / 7$ & $(1 / 9,1 / 7,1 / 5)$ \\
\hline 9 & $(7,9,11)$ & $1 / 9$ & $(1 / 11,1 / 9,1 / 7)$ \\
\hline
\end{tabular}

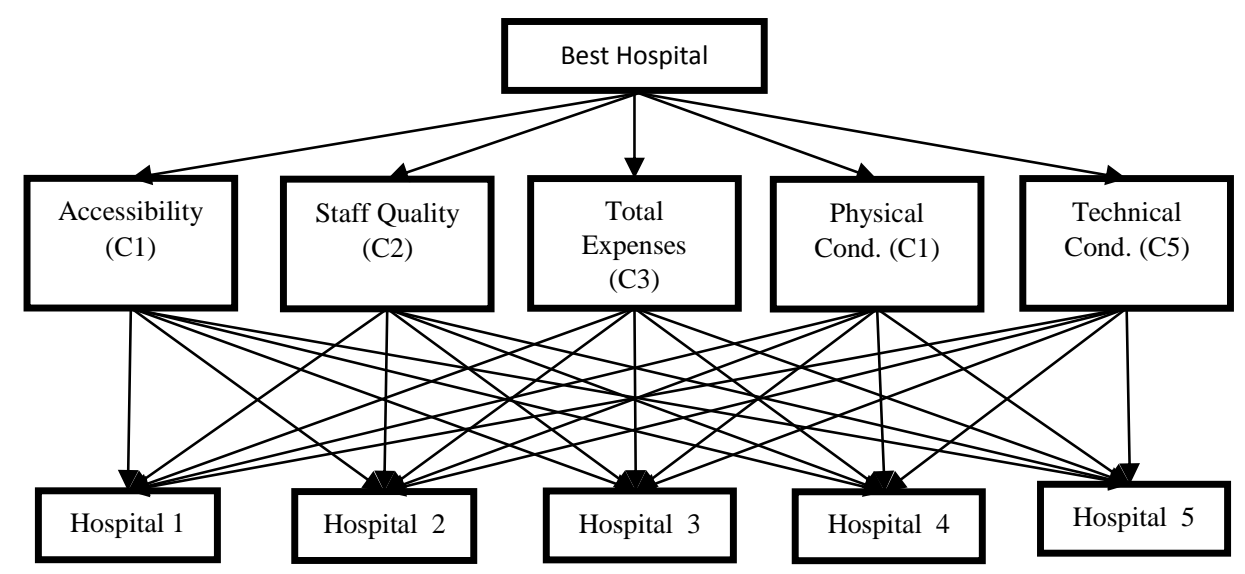

Figure 3. Hierarchical structure for decision problem. 
Table 3. Pairwise comparisons of criteria respect to goal.

\begin{tabular}{|c|c|c|c|c|c|c|c|c|c|c|c|c|c|c|c|}
\hline & \multicolumn{3}{|c|}{$\mathrm{C} 1$} & \multicolumn{4}{c|}{$\mathrm{C} 2$} & \multicolumn{3}{c|}{$\mathrm{C} 3$} & \multicolumn{3}{c|}{$\mathrm{C} 4$} & \multicolumn{3}{c|}{$\mathrm{C} 5$} \\
\hline & $\mathrm{L}$ & $\mathrm{M}$ & $\mathrm{U}$ & $\mathrm{L}$ & $\mathrm{M}$ & $\mathrm{U}$ & $\mathrm{L}$ & $\mathrm{M}$ & $\mathrm{U}$ & $\mathrm{L}$ & $\mathrm{M}$ & $\mathrm{U}$ & $\mathrm{L}$ & $\mathrm{M}$ & $\mathrm{U}$ \\
\hline $\mathrm{C} 1$ & 1 & 1 & 1 & $1 / 9$ & $1 / 7$ & $1 / 5$ & $1 / 9$ & $1 / 7$ & $1 / 5$ & $1 / 9$ & $1 / 7$ & $1 / 5$ & $1 / 9$ & $1 / 7$ & $1 / 5$ \\
\hline $\mathrm{C} 2$ & 5 & 7 & 9 & 1 & 1 & 1 & 5 & 7 & 9 & 5 & 7 & 9 & 5 & 7 & 9 \\
\hline $\mathrm{C} 3$ & 5 & 7 & 9 & $1 / 9$ & $1 / 7$ & $1 / 5$ & 1 & 1 & 1 & $1 / 9$ & $1 / 7$ & $1 / 5$ & $1 / 9$ & $1 / 7$ & $1 / 5$ \\
\hline $\mathrm{C} 4$ & 5 & 7 & 9 & $1 / 9$ & $1 / 7$ & $1 / 5$ & 5 & 7 & 9 & 1 & 1 & 1 & $1 / 7$ & $1 / 5$ & $1 / 3$ \\
\hline $\mathrm{C} 5$ & 5 & 7 & 9 & $1 / 9$ & $1 / 7$ & $1 / 5$ & 5 & 7 & 9 & 3 & 5 & 7 & 1 & 1 & 1 \\
\hline
\end{tabular}

Step 3: Fuzzy weights of criteria are calculated by using geometric mean operator [13]. Lower, moderate and upper values for criteria weights are given in Table 4.

Step 4: Pairwise comparison matrices for alternatives in terms of each criterion are formed. Five comparison matrices for alternatives in terms of criteria are given in Table 5-9.
Table 4. Fuzzy weights of criteria.

\begin{tabular}{|c|c|c|c|}
\hline & $\mathbf{L}$ & $\mathbf{M}$ & $\mathbf{U}$ \\
\hline C1 & 0,020 & 0,025 & 0,032 \\
\hline C2 & 0,425 & 0,557 & 0,681 \\
\hline C3 & 0,043 & 0,054 & 0,069 \\
\hline C4 & 0,098 & 0,126 & 0,164 \\
\hline C5 & 0,179 & 0,239 & 0,302 \\
\hline
\end{tabular}

Table 5. Pairwise comparisons of alternatives respect to C1.

\begin{tabular}{|c|c|c|c|c|c|c|c|c|c|c|c|c|c|c|c|}
\hline & \multicolumn{4}{|c|}{ H1 } & \multicolumn{4}{c|}{ H2 } & \multicolumn{3}{c|}{ H3 } & \multicolumn{3}{c|}{ H4 } & \multicolumn{3}{c|}{ H5 } \\
\hline & $\mathrm{L}$ & $\mathrm{M}$ & $\mathrm{U}$ & $\mathrm{L}$ & $\mathrm{M}$ & $\mathrm{U}$ & $\mathrm{L}$ & $\mathrm{M}$ & $\mathrm{U}$ & $\mathrm{L}$ & $\mathrm{M}$ & $\mathrm{U}$ & $\mathrm{L}$ & $\mathrm{M}$ & $\mathrm{U}$ \\
\hline H1 & 1 & 1 & 1 & 7 & 9 & 11 & 7 & 9 & 11 & 7 & 9 & 11 & 7 & 9 & 11 \\
\hline H2 & $1 / 11$ & $1 / 9$ & $1 / 7$ & 1 & 1 & 1 & 3 & 5 & 7 & 3 & 5 & 7 & 5 & 7 & 9 \\
\hline H3 & $1 / 11$ & $1 / 9$ & $1 / 7$ & $1 / 7$ & $1 / 5$ & $1 / 3$ & 1 & 1 & 1 & 3 & 5 & 7 & 5 & 7 & 9 \\
\hline H4 & $1 / 11$ & $1 / 9$ & $1 / 7$ & $1 / 7$ & $1 / 5$ & $1 / 3$ & $1 / 7$ & $1 / 5$ & $1 / 3$ & 1 & 1 & 1 & 5 & 7 & 9 \\
\hline H5 & $1 / 11$ & $1 / 9$ & $1 / 7$ & $1 / 9$ & $1 / 7$ & $1 / 5$ & $1 / 9$ & $1 / 7$ & $1 / 5$ & $1 / 9$ & $1 / 7$ & $1 / 5$ & 1 & 1 & 1 \\
\hline
\end{tabular}

Table 6. Pairwise comparisons of alternatives respect to $C 2$.

\begin{tabular}{|c|c|c|c|c|c|c|c|c|c|c|c|c|c|c|c|}
\hline & \multicolumn{4}{|c|}{ H1 } & \multicolumn{4}{c|}{ H2 } & \multicolumn{3}{c|}{ H3 } & \multicolumn{3}{c|}{ H4 } & \multicolumn{3}{c|}{ H5 } \\
\hline & $\mathrm{L}$ & $\mathrm{M}$ & $\mathrm{U}$ & $\mathrm{L}$ & $\mathrm{M}$ & $\mathrm{U}$ & $\mathrm{L}$ & $\mathrm{M}$ & $\mathrm{U}$ & $\mathrm{L}$ & $\mathrm{M}$ & $\mathrm{U}$ & $\mathrm{L}$ & $\mathrm{M}$ & $\mathrm{U}$ \\
\hline H1 & 1 & 1 & 1 & 5 & 7 & 9 & 5 & 7 & 9 & 7 & 9 & 11 & 5 & 7 & 9 \\
\hline H2 & $1 / 9$ & $1 / 7$ & $1 / 5$ & 1 & 1 & 1 & $1 / 9$ & $1 / 7$ & $1 / 5$ & 5 & 7 & 9 & 3 & 5 & 7 \\
\hline H3 & $1 / 9$ & $1 / 7$ & $1 / 5$ & 5 & 7 & 9 & 1 & 1 & 1 & 5 & 7 & 9 & 3 & 5 & 7 \\
\hline H4 & $1 / 11$ & $1 / 9$ & $1 / 7$ & $1 / 9$ & $1 / 7$ & $1 / 5$ & $1 / 9$ & $1 / 7$ & $1 / 5$ & 1 & 1 & 1 & $1 / 9$ & $1 / 7$ & $1 / 5$ \\
\hline H5 & $1 / 9$ & $1 / 7$ & $1 / 5$ & $1 / 7$ & $1 / 5$ & $1 / 3$ & $1 / 7$ & $1 / 5$ & $1 / 3$ & 5 & 7 & 9 & 1 & 1 & 1 \\
\hline
\end{tabular}

Table 7. Pairwise comparisons of alternatives respect to C3.

\begin{tabular}{|l|c|c|c|c|c|c|c|c|c|c|c|c|c|c|c|c|}
\hline & \multicolumn{3}{|c|}{ H1 } & \multicolumn{4}{c|}{ H2 } & \multicolumn{4}{c|}{ H3 } & \multicolumn{3}{c|}{ H4 } & \multicolumn{3}{c|}{ H5 } \\
\hline & $\mathrm{L}$ & $\mathrm{M}$ & $\mathrm{U}$ & $\mathrm{L}$ & $\mathrm{M}$ & $\mathrm{U}$ & $\mathrm{L}$ & $\mathrm{M}$ & $\mathrm{U}$ & $\mathrm{L}$ & $\mathrm{M}$ & $\mathrm{U}$ & $\mathrm{L}$ & $\mathrm{M}$ & $\mathrm{U}$ \\
\hline H1 & 1 & 1 & 1 & $1 / 11$ & $1 / 9$ & $1 / 7$ & $1 / 9$ & $1 / 7$ & $1 / 5$ & $1 / 11$ & $1 / 9$ & $1 / 7$ & $1 / 9$ & $1 / 7$ & $1 / 5$ \\
\hline H2 & 7 & 9 & 11 & 1 & 1 & 1 & 7 & 9 & 11 & 5 & 7 & 9 & 7 & 9 & 11 \\
\hline H3 & 5 & 7 & 9 & $1 / 11$ & $1 / 9$ & $1 / 7$ & 1 & 1 & 1 & $1 / 9$ & $1 / 7$ & $1 / 5$ & 3 & 5 & 7 \\
\hline H4 & 7 & 9 & 11 & $1 / 9$ & $1 / 7$ & $1 / 5$ & 5 & 7 & 9 & 1 & 1 & 1 & 5 & 7 & 9 \\
\hline H5 & 5 & 7 & 9 & $1 / 11$ & $1 / 9$ & $1 / 7$ & $1 / 7$ & $1 / 5$ & $1 / 3$ & $1 / 9$ & $1 / 7$ & $1 / 5$ & 1 & 1 & 1 \\
\hline
\end{tabular}

Table 8. Pairwise comparisons of alternatives respect to C4.

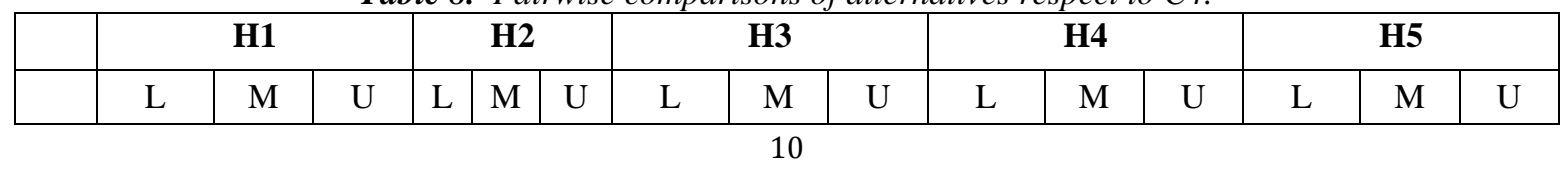




\begin{tabular}{|c|c|c|c|c|c|c|c|c|c|c|c|c|c|c|c|}
\hline H1 & 1 & 1 & 1 & 7 & 9 & 11 & 5 & 7 & 9 & 5 & 7 & 9 & 5 & 7 & 9 \\
\hline H2 & $1 / 11$ & $1 / 9$ & $1 / 7$ & 1 & 1 & 1 & $1 / 11$ & $1 / 9$ & $1 / 7$ & $1 / 11$ & $1 / 9$ & $1 / 7$ & $1 / 11$ & $1 / 9$ & $1 / 7$ \\
\hline H3 & $1 / 9$ & $1 / 7$ & $1 / 5$ & 7 & 9 & 11 & 1 & 1 & 1 & $1 / 9$ & $1 / 7$ & $1 / 5$ & $1 / 9$ & $1 / 7$ & $1 / 5$ \\
\hline H4 & $1 / 9$ & $1 / 7$ & $1 / 5$ & 7 & 9 & 11 & 5 & 7 & 9 & 1 & 1 & 1 & 3 & 5 & 7 \\
\hline H5 & $1 / 9$ & $1 / 7$ & $1 / 5$ & 7 & 9 & 11 & 5 & 7 & 9 & $1 / 7$ & $1 / 5$ & $1 / 3$ & 1 & 1 & 1 \\
\hline
\end{tabular}

Table 9. Pairwise comparisons of alternatives respect to $C 5$.

\begin{tabular}{|l|c|c|c|c|c|c|c|c|c|c|c|c|c|c|c|}
\hline & \multicolumn{4}{|c|}{ H1 } & \multicolumn{3}{c|}{ H2 } & \multicolumn{4}{c|}{ H3 } & \multicolumn{3}{c|}{ H4 } & \multicolumn{3}{c|}{ H5 } \\
\hline & $\mathrm{L}$ & $\mathrm{M}$ & $\mathrm{U}$ & $\mathrm{L}$ & $\mathrm{M}$ & $\mathrm{U}$ & $\mathrm{L}$ & $\mathrm{M}$ & $\mathrm{U}$ & $\mathrm{L}$ & $\mathrm{M}$ & $\mathrm{U}$ & $\mathrm{L}$ & $\mathrm{M}$ & $\mathrm{U}$ \\
\hline H1 & 1 & 1 & 1 & 7 & 9 & 11 & 3 & 5 & 7 & $1 / 9$ & $1 / 7$ & $1 / 5$ & 3 & 5 & 7 \\
\hline H2 & $1 / 11$ & $1 / 9$ & $1 / 7$ & 1 & 1 & 1 & $1 / 11$ & $1 / 9$ & $1 / 7$ & $1 / 1$ & $1 / 9$ & $1 / 7$ & $1 / 11$ & $1 / 9$ & $1 / 7$ \\
\hline H3 & $1 / 7$ & $1 / 5$ & $1 / 3$ & 7 & 9 & 11 & 1 & 1 & 1 & $1 / 9$ & $1 / 7$ & $1 / 5$ & 3 & 5 & 7 \\
\hline H4 & 5 & 7 & 9 & 7 & 9 & 11 & 5 & 7 & 9 & 1 & 1 & 1 & 7 & 9 & 11 \\
\hline H5 & $1 / 7$ & $1 / 5$ & $1 / 3$ & 7 & 9 & 11 & $1 / 7$ & $1 / 5$ & $1 / 3$ & $1 / 1$ & $1 / 9$ & $1 / 7$ & 1 & 1 & 1 \\
\hline
\end{tabular}

Table 10. Fuzzy priorities of hospitals.

\begin{tabular}{|c|c|c|c|c|c|c|c|c|c|c|c|c|c|c|c|}
\hline & \multicolumn{3}{|c|}{ C1 } & \multicolumn{3}{|c|}{$\mathrm{C} 2$} & \multicolumn{3}{|c|}{$\mathrm{C3}$} & \multicolumn{3}{|c|}{$\mathrm{C4}$} & \multicolumn{3}{|c|}{ C5 } \\
\hline & $\mathrm{L}$ & M & $\mathrm{U}$ & $\mathrm{L}$ & $\mathrm{M}$ & $\mathrm{U}$ & $\mathrm{L}$ & $\mathrm{M}$ & $\mathrm{U}$ & $\mathrm{L}$ & $\mathrm{M}$ & $\mathrm{U}$ & $\mathrm{L}$ & $\mathrm{M}$ & $\mathrm{U}$ \\
\hline H1 & 0,512 & 0,626 & 0,735 & 0,446 & 0,574 & 695 & 0,017 & 0,020 & 0,026 & 0,435 & 0,560 & 0,678 & 0,164 & 0,223 & 0,283 \\
\hline $\mathrm{H} 2$ & 0,143 & 0,195 & 0,247 & 0,082 & 0,108 & 0,139 & 0,474 & 0,590 & 0,699 & 0,016 & 0,019 & 0,024 & 0,016 & 0,019 & 0,023 \\
\hline H3 & 0,078 & 0,103 & 0,135 & 0,176 & 0,234 & 0,297 & 0,073 & 0,095 & 0,120 & 0,044 & 0,054 & 0,069 & 0,089 & 0,117 & 0,154 \\
\hline $\mathrm{H4}$ & 0,042 & 0,054 & 0,073 & 0,019 & 0,023 & 0,030 & 0,194 & 0,245 & 0,301 & 0,183 & 0,240 & 0,301 & 0,461 & 0,583 & 0,699 \\
\hline H5 & 0,018 & 0,022 & 0,028 & 0,047 & 0,060 & 0,083 & 0,040 & 0,050 & 0,065 & 0,100 & 0,126 & 0,164 & 0,047 & 0,058 & 0,078 \\
\hline
\end{tabular}

Table 11. Fuzzy and defuzzified scores of hospitals.

\begin{tabular}{|c|c|c|c|c|}
\hline & L & M & U & Defuzzified Score \\
\hline H1 & 0,032 & 0,050 & 0,078 & 0,052 \\
\hline H2 & 0,312 & 0,519 & 0,771 & $\mathbf{0 , 5 3 0}$ \\
\hline H3 & 0,020 & 0,033 & 0,054 & 0,035 \\
\hline H4 & 0,088 & 0,144 & 0,231 & 0,152 \\
\hline H5 & 0,045 & 0,076 & 0,127 & 0,081 \\
\hline
\end{tabular}

Step 5: Fuzzy performance values of alternatives with respect to all criteria are calculated by using geometric mean and presented in Table 10.

Step 6: Fuzzy weighted scores for alternatives are calculated by multiplication of criteria weights and alternative priorities.

Step 7: The best hospital is determined by defuzzification of fuzzy weighted scores according to formula in Ansari et al. [14]. Fuzzy and defuzzified scores of hospitals are presented in Table 11.

The best hospital for pregnancy process follow-up is determined as Hospital 2. The rank of hospital goes on as Hospital 4, Hospital 5, Hospital 1 and Hospital 3.

\section{Conclusions and Recommendations}

Having a child brings great responsibilities for parents. A number of decisions are arising from the beginning of the pregnancy process. These decisions are generally difficult, because they consist different criteria to consider and a number of alternative to evaluate. First decision to be made during the pregnancy process is selection of a maternity hospital. 
The main objective of this paper is to present a scientific basis to determine the best maternity hospital for pregnant women. For this purpose, a fuzzy decision making model based on Analytic Hierarchy Process (AHP) is proposed. To illustrate the proposed model, a case study is presented.

In further studies, different selection criteria can be considered in the model. Using of hybrid decision making approaches or other fuzzy approaches such as Intuitionistic Fuzzy Sets or Hesitant Fuzzy Sets can be performed.

\section{References}

[1] Kabak Mehmet, Sağlam Fatih, Aktaş Ahmet, "Usability analysis of different distance measures on TOPSIS" Journal of the Faculty of Engineering and Architecture of Gazi University, 32, 35-43 (2017)

[2] T. L. Saaty, The Analytic Hierarchy Process, McGraw-Hill, New York 1980

[3] Dağdeviren, Metin "Personnel selection with Fuzzy Analytical Hierarchy Process and an application" Journal of the Faculty of Engineering and Architecture of Gazi University, 22, 791-799 (2007)

[4] Wang, J., M. Li, Y. Liu, H. Zhang, W. Zou, L. Cheng. "Safety assessment of shipping routes in the South China Sea based on the fuzzy analytic hierarchy process" Safety Science, 62, 46-57 (2014)

[5] Calabrese, A., R. Costa, T. Menichini. "Using Fuzzy AHP to manage Intellectual Capital assets: An application to the ICT service industry" Expert Systems with Applications, 40, 3747-3755 (2013)

[6] García, J.L., A. Alvarado, J. Blanco, E. Jiménez, A.A. Maldonado, G. Cortés, "Multi-attribute evaluation and selection of sites for agricultural product warehouses based on an Analytic Hierarchy Process" Computers and Electronics in Agriculture, 100, 60-69 (2014)

[7] Caputo, A. C., P. M. Pelagagge, P. Salini. "AHPbased methodology for selecting safety devices of industrial machinery" Safety Science, 53, 202-218 (2013)

[8] Oztaysi, B. "A decision model for information technology selection using AHP integrated TOPSIS-Grey: The case of content management systems" Knowledge-Based Systems, 70, 44-54 (2014)

[9] Ishizaka, A., N. H. Nguyen. "Calibrated fuzzy AHP for current bank account selection", Expert Systems with Applications, 40, 3775-3783 (2013)

[10] Junior, F. R. L., L. Osiro, L. C. R. Carpinetti. “A comparison between Fuzzy AHP and Fuzzy TOPSIS methods to supplier selection" Applied Soft Computing, 21, 194-209 (2014)

[11] Efe, B. "An integrated fuzzy multi criteria group decision making approach for ERP system selection" Applied Soft Computing, 38, 106-117 (2016)
[12] Zadeh, L.A. "Fuzzy Sets" Information and Control, $8,338-353$ (1965)

[13] Rouyendegh, B. D., T. E. Erkan. "Selection of Academic Staff Using The Fuzzy Analytic Hierarchy Process (FAHP): A Pilot Study" Technical Gazette, 19, 923-929 (2012)

[14] Ansari, S. R., P. K. Mittal, R. Chandna. "Multicriteria decision making using fuzzy logic approach for evaluating the manufacturing flexibility" Journal of Engineering and Technology Research, 2, 237-244 (2010) 